\title{
Assessment of Functions of the Autonomic Nervous System in the Elderly with Different Comorbid Factors
}

\author{
Sushma S. ${ }^{1}$ Medha Y. Rao ${ }^{1}$ Shaikh Mohammed Aslam, \\ ${ }^{1}$ Department of General Medicine, M.S. Ramaiah Medical College \\ and Hospitals, Bengaluru, Karnataka, India
}

\begin{abstract}
Address for correspondence Shaikh Mohammed Aslam, MD, Department of General Medicine, M.S. Ramaiah Medical College and Hospitals, M S R Nagar, MSRIT Post, Bengaluru, Karnataka, 560054, India (e-mail: drmdaslam@yahoo.com).
\end{abstract}

J Neurosci Rural Pract:2021;12:80-87

\begin{abstract}
Keywords

- blood pressure

- heart rate

- nervous system

- autonomic nervous system diseases
\end{abstract}

Background Studies in healthy elderly patients have shown the prevalence of autonomic dysfunction (AD) in the range of 20 to $30 \%$. However, there is paucity in data pertaining to $A D$ in the elderly in the Indian context.

Objective To assess the prevalence of $A D$ in the elderly irrespective of their comorbidity status.

Methods A total of 141 elderly patients with or without comorbidities/symptoms of $A D$ were included. Demographic and clinical details of the patients were recorded. Autonomic function tests (AFTs) such as deep breathing test, Valsalva ratio, orthostatic heart rate $(\mathrm{OHR})$, isometric handgrip test, and orthostatic blood pressure were performed based on Ewing's battery of tests. The sensitivity, specificity, positive predictive value, negative predictive value, and the accuracy of AFTs were evaluated.

Results Most patients $(n=85)$ were aged between 60 and 69 years, with a male predominance $(58.87 \%)$. Hypertension and diabetes mellitus were the most common comorbidities. Postural hypotension was the most common symptom of AD. With advancing age, symptoms of $A D$ manifested significantly more. Overall, $73.8 \%$ of patients had AD, of whom $45.4 \%$ had early AD. Number of AD symptoms, glycated hemoglobin (HbA1c) level, and comorbid factors (diabetes and hypertension) were significantly associated with the results of AFTs $(p<0.05)$. AFTs were highly significant with respect to the results obtained $(p<0.001)$. Deep breathing test, abnormal in majority of study patients, has a sensitivity of $93.3 \%$ and OHR has a specificity of $81.1 \%$ to determine AD.

Conclusion The study concludes that age itself is an independent predictor of AD, which increases in severity if associated with comorbidities.

\section{Introduction}

The autonomic nervous system (ANS) is the part of the nervous system that comprises the parasympathetic, sympathetic, and enteric nervous systems. ANS plays a vital role in homeostasis. ${ }^{1}$ However, with advancing age, functions of the systems may be affected and lead to autonomic dysfunction $(\mathrm{AD}) .^{2} \mathrm{AD}$ results from overactivity or loss of regulation of autonomic circuits. ${ }^{3}$ Clinical symptoms of autonomic disturbances are multiple and categorized as cardiac, gastrointestinal, urinary, and so on. ${ }^{4}$ Comorbidities such as diabetes mellitus (DM) and hypertension show an increased incidence as age advances; therefore, most autonomic disturbances remain unassessed, although their recognition would assist in the effective treatment of the geriatric population.
DOI https://doi.org/ 10.1055/s-0040-1718854 ISSN 0976-3147.
(C) 2020. Association for Helping Neurosurgical Sick People.

This is an open access article published by Thieme under the terms of the Creative Commons Attribution-NonDerivative-NonCommercial-License, permitting copying and reproduction so long as the original work is given appropriate credit. Contents may not be used for commercial purposes, or adapted, remixed, transformed or built upon. (https://creativecommons.org/licenses/by-nc-nd/4.0/)

Thieme Medical and Scientific Publishers Pvt. Ltd. A-12, 2nd Floor, Sector 2, Noida-201301 UP, India 
In the geriatric population, symptoms of $\mathrm{AD}$ are atypical and subtle; therefore, the index of suspicion is lower. ${ }^{5}$ Sympathetic and parasympathetic divisions of ANS that play important roles in vital functions mature with time; however, the degree of the variations mainly depends on aging due to their divergent neural pathways. Hence, normal aging is considered as a significant confounding factor for the diagnosis of ANS dysfunction. Chronic diseases such as hypertension, DM, arthritis, and chronic kidney disease (CKD) that are increasing worldwide at a faster pace were also found to be associated with ANS dysfunction..$^{6,7}$ Cardiovascular noninvasive reflex tests proposed by Ewing and Clarke. ${ }^{8}$ aided in the successful identification of AD. The tests include heart rate (HR) response to deep breathing, Valsalva maneuver, orthostatic position for assessing parasympathetic functions and blood pressure (BP) response to sustained handgrip, and orthostatic position for sympathetic functions. ${ }^{6}$

Several studies have assessed AD in the elderly. ${ }^{2,6,9,10}$ Healthy elderly patients without any comorbidities were included, and autonomic function tests (AFTs) showed the prevalence of $\mathrm{AD}$ ranging from 20 to $30 \%$. $^{2,6,9,10}$ Moreover, investigations in the elderly population in the Indian context are quite scarce. This study intended to assess the prevalence of AD in the elderly irrespective of their comorbidity status.

\section{Methods}

This cross-sectional study was conducted on 141 elderly patients who attended the Department of General Medicine over 24 months from October 2016 to September 2018. Ethical clearance (SS-1/EC/18/2016) was sought from the Institutional Ethical and Research Committee before study initiation. Outpatient and hospitalized patients aged more than or equal to 60 years, of either gender, with or without symptoms, were included in the study. Patients with inherited autonomic neuropathies, primarily acquired autonomic neuropathy, or acute illness were excluded. Patients on drugs known to affect autonomic activity, such as clonidine ( $\alpha$-blockers), propranolol ( $\beta$-blockers), cisplatin, and vincristine (chemotherapeutic agents), were also exempted.

Baseline characteristics including demographic data, detailed history, clinical examinations, and laboratory investigations of patients including results of AFTs were noted in a predesigned pro forma. All patients were instructed to avoid caffeine and nicotine for 3 to 4 hours and alcohol for 8 hours before testing. They were made to lie down for 30 minutes in a quiet room with neutral temperature and humidity prior to testing. Patients were then instructed to lie down in the supine position with the head elevated to 30 degrees. Electrocardiogram (ECG) electrodes were connected to record the resting HR from lead II ECG using the RMS VAGUS HRV (2008) software (Recorders \& Medicare Systems Pvt Ltd, India). Simple and noninvasive AFTs were then performed on the patients, such as HR response to the Valsalva maneuver, deep breathing, sustained handgrip, and standing as well as BP response to standing, to determine the cardiovagal (parasympathetic) and adrenergic (sympathetic) responses. Deep breathing test, Valsalva ratio, and orthostatic HR test represent parasympathetic function, whereas isometric handgrip test and orthostatic BP test represent sympathetic function. Interpretation of test results was done according to Ewing and Clarke. ${ }^{8}$ All tests were performed after explaining the procedure to the patient and obtaining their informed consent. In case the patient complained of discomfort, the test was abandoned.

Initially, patients were asked to blow into a special tube connected to the mercury manometer, and the pressure was maintained at $40 \mathrm{~mm} \mathrm{Hg}$ for 15 seconds to measure HR response to the Valsalva maneuver. The procedure was performed three times to determine the mean value. Valsalva ratio was calculated between the longest and shortest RR interval in phase 4 and phase 2 . Next, patients were made to take five breaths (with 5 seconds of inhalation and 5 seconds of exhalation per breath) for a total of 10 times to measure HR response to deep breathing. The mean longest and shortest RR interval during expiration and inspiration was calculated to estimate HR difference. Finally, patients were instructed to rest in the supine position and then made to be upright immediately to record HR response to standing on ECG continuously using the 30:15 ratio (ratio between 30 th [maximal] and 15th [minimal] heartbeat).

Patients were made to lie down, and BP was measured immediately after standing, that is, at 1, 2, and 5 minutes, to measure BP response to standing. Sustained handgrip test was performed using a handgrip dynamometer. During the test, patients were made to press the dynamometer to measure the maximum voluntary contraction and later instructed to press the dynamometer at about one-third of the maximum contraction strength for 3 to 5 minutes to estimate the diastolic BP. The BP measurements were recorded three times before and at 1-minute intervals on the other arm. A difference of $>15 \mathrm{~mm} \mathrm{Hg}$ between the highest and average diastolic BP at rest was considered normal.

\section{Statistical Analysis}

A previous study ${ }^{2}$ revealed that $23.34 \%$ of patients aged 61 to 70 years showed autonomic nerve dysfunction. Based on the findings, sample size was calculated considering absolute precision of $7 \%$ and confidence level $(\mathrm{CI})$ of $95 \%$ to derive a minimum of 141 sample size.

SPSS version 18 (IBM Corp.) and $\mathrm{R}$ Version 3.2.2 ( $R$ Foundation for Statistical Computing) were used to analyze the data. All quantitative parameters were expressed in terms of descriptive statistics (mean \pm standard deviation and interquartile range). Qualitative parameters were expressed as percentage. Differences in the mean values were tested for statistical significance using the analysis of variance or Kruskal-Wallis test. Association between categorical variables was tested for statistical significance using the chi-square or Fischer exact test. Logistic regression analysis was performed to determine the factors affecting the autonomic function in the elderly. Sensitivity, specificity, positive 
predictive value (PPV), negative predictive value (NPV), and accuracy were computed to determine the diagnostic properties of test/criteria in relation to the results. Significance was assessed at the level of $5 \%$. A $p$-value of $<0.05$ was regarded as statistically significant.

\section{Results}

Of 141 patients, $60.3 \%$ were aged 60 to 69 years, with a male predominance (58.87\%). DM was the most common comorbidity in patients aged 60 to 69 years (37.6\%) followed by hypertension in patients aged $>70$ years (52.4\%). Glycated hemoglobin (HbA1c) and none of the comorbidities had a significant association with age in this study group of patients $(p>0.05)$. Around $43.3 \%$ of study patients were symptomatic. Among all symptomatic elderly patients $(n=61)$, postural hypotension was significantly the most common symptom (28.4\%). It was observed that with advancing age, symptoms of AD manifested more, and age was found to be statistically significant $(p<0.02 ;$ - Table 1$)$.

None of the AFTs were significantly associated with age $(p>0.05)$. Deep breathing test, Valsalva ratio, and orthostatic HR test were abnormal in 128 patients, whereas isometric handgrip and orthostatic BP tests were abnormal in 27 patients. Deep breathing test (59.6\%) was abnormal in most patients followed by Valsalva ratio (24.8\%) and isometric handgrip test (16.3\%), indicating that parasympathetic dysfunction was found to be more than sympathetic dysfunction in elderly patients ( - Table 2 ).

The prevalence of $\mathrm{AD}$ was $73.8 \%$ in this study. Early $\mathrm{AD}$ was seen in $45.4 \%$ of patients, definitive $\mathrm{AD}$ in $9.9 \%$, severe $\mathrm{AD}$ in $13.5 \%$, and atypical $\mathrm{AD}$ in $5 \%$. It was found that age, gender, number of comorbidities, and symptoms of $A D$ showed no significant association with the results of AFTs ( $p>0.05$ ), whereas the number of AD symptoms, HbA1c, and comorbidities (DM and hypertension) showed a significant association with the results of AFTs $(p<0.05$;

\section{- Table 3).}

All tests performed for detecting $A D$ were statistically significant with respect to the results obtained $(p<0.001$; - Table 4). Of various AFTs performed, HR response to deep breathing test $(59.57 \%)$ was found to be the most sensitive test to assess abnormal $\mathrm{AD}$ in the elderly followed by Valsalva ratio (24.82\%), isometric handgrip test (16.31\%), and HR response to standing (6.38\%), with the least being BP response to standing (2.83\%).

Preexisting DM, postural hypertension, gastrointestinal symptoms, and bladder symptoms were significantly associated with $\mathrm{AD}$ in the elderly. Multinomial logistic regression revealed that preexisting DM (adjusted odds ratio

Table 1 Comorbidities, HbA1c, and symptoms of autonomic dysfunction in different age groups

\begin{tabular}{|c|c|c|c|}
\hline \multirow[t]{2}{*}{ Variables } & \multicolumn{3}{|c|}{ Age (years) } \\
\hline & $60-69(n=85)$ & $70-79(n=42)$ & $>80(n=14)$ \\
\hline \multicolumn{4}{|l|}{ Comorbidities } \\
\hline Diabetes mellitus $(n=52)$ & $32(37.6 \%)$ & $16(38.1 \%)$ & $4(28.6 \%)$ \\
\hline Hypertension $(n=58)$ & $30(35.3 \%)$ & $22(52.4 \%)$ & $6(42.9 \%)$ \\
\hline Hypothyroidism $(n=18)$ & $13(15.3 \%)$ & $4(9.5 \%)$ & $1(7.1 \%)$ \\
\hline History of Ischemic heart disease $(n=28)$ & $16(18.8 \%)$ & $11(26.2 \%)$ & $1(7.1 \%)$ \\
\hline History of cerebrovascular accident $(n=17)$ & $10(11.8 \%)$ & $6(14.3 \%)$ & $1(7.1 \%)$ \\
\hline Chronic kidney disease $(n=18)$ & $11(13 \%)$ & $6(14 \%)$ & $1(7.1 \%)$ \\
\hline Chronic obstructive pulmonary disorder $(n=22)$ & $15(18 \%)$ & $5(12 \%)$ & $2(14 \%)$ \\
\hline Bronchial asthma $(n=6)$ & $5(6 \%)$ & $1(2 \%)$ & 0 \\
\hline Chronic liver disease $(n=13)$ & $8(9 \%)$ & $4(10 \%)$ & $1(7.1 \%)$ \\
\hline Cancer $(n=3)$ & 0 & $3(7 \%)$ & 0 \\
\hline Heart failure $(n=9)$ & $7(8 \%)$ & $2(5 \%)$ & 0 \\
\hline \multicolumn{4}{|l|}{ HbA1c } \\
\hline$<7(n=24)$ & $14(16.5 \%)$ & $9(21.4 \%)$ & $1(7.1 \%)$ \\
\hline $7-9(n=20)$ & $13(15.3 \%)$ & $4(9.5 \%)$ & $3(21.4 \%)$ \\
\hline$>9(n=8)$ & $5(5.9 \%)$ & $3(7.1 \%)$ & 0 \\
\hline Nondiabetic $(n=89)$ & $53(62.4 \%)$ & $26(61.9 \%)$ & $10(71.4 \%)$ \\
\hline \multicolumn{4}{|l|}{ Symptoms of $A D^{a}$} \\
\hline Postural hypotension $(n=40)$ & $16(18.8 \%)$ & $8(19 \%)$ & $6(42.9 \%)$ \\
\hline Gastrointestinal symptoms ${ }^{a}(n=21)$ & $9(10.6 \%)$ & $7(16.7 \%)$ & $5(37.7 \%)$ \\
\hline Bladder symptoms $(n=18)$ & $8(9.4 \%)$ & $7(16.7 \%)$ & $3(21.4 \%)$ \\
\hline Sudomotor symptoms $(n=2)$ & $2(2.4 \%)$ & 0 & 0 \\
\hline
\end{tabular}

Abbreviations: AD, autonomic dysfunction; HbA1c, glycated hemoglobin.

asignificant. 
Table 2 Autonomic function tests in elderly patients of different age groups

\begin{tabular}{|c|c|c|c|}
\hline \multirow[t]{2}{*}{ Criteria } & \multicolumn{3}{|c|}{ Age (years) } \\
\hline & $60-69(n=85)$ & $70-79(n=42)$ & $>80(n=14)$ \\
\hline \multicolumn{4}{|l|}{ Deep breathing test } \\
\hline Normal $(n=37)$ & $23(27.1 \%)$ & $10(23.8 \%)$ & $4(28.6 \%)$ \\
\hline Borderline $(n=20)$ & $12(14.1 \%)$ & $1(14.3 \%)$ & $2(14.3 \%)$ \\
\hline Abnormal $(n=84)$ & $50(58.8 \%)$ & $26(61.9 \%)$ & $8(57.1 \%)$ \\
\hline \multicolumn{4}{|l|}{ Valsalva ratio } \\
\hline Normal $(n=64)$ & $39(45.9 \%)$ & $20(47.6 \%)$ & $5(35.7 \%)$ \\
\hline Borderline $(n=42)$ & $29(34.1 \%)$ & $10(23.8 \%)$ & $3(21.4 \%)$ \\
\hline Abnormal $(n=35)$ & $17(20 \%)$ & $12(28.6 \%)$ & $6(42.9 \%)$ \\
\hline \multicolumn{4}{|c|}{ Orthostatic test: heart rate } \\
\hline Normal $(n=125)$ & 78 (91.8\%) & $36(83.3 \%)$ & $12(85.7 \%)$ \\
\hline Borderline $(n=7)$ & $3(3.5 \%)$ & $4(9.5 \%)$ & 0 \\
\hline Abnormal $(n=9)$ & $4(4.7 \%)$ & $3(7.1 \%)$ & $2(14.3 \%)$ \\
\hline \multicolumn{4}{|l|}{ Isometric handgrip test } \\
\hline Normal $(n=67)$ & $39(45.9 \%)$ & $19(45.2 \%)$ & $9(64.3 \%)$ \\
\hline Borderline $(n=51)$ & $31(36.5 \%)$ & $16(38.1 \%)$ & $4(28.6 \%)$ \\
\hline Abnormal $(n=23)$ & $15(17.6 \%)$ & $7(16.7 \%)$ & $1(7.1 \%)$ \\
\hline \multicolumn{4}{|c|}{ Orthostatic test: blood pressure } \\
\hline Normal $(n=114)$ & $68(80 \%)$ & $35(83.3 \%)$ & 11 (78.6\%) \\
\hline Borderline $(n=23)$ & $14(16.5 \%)$ & $6(14.3 \%)$ & $3(21.4 \%)$ \\
\hline Abnormal $(n=4)$ & $3(3.5 \%)$ & $1(2.4 \%)$ & 0 \\
\hline
\end{tabular}

$[\mathrm{OR}]=2.55 ; 95 \% \mathrm{CI}: 1.27-5.20 ; p<0.008)$, presence of gastrointestinal symptoms (adjusted OR $=38,53$; 95\% CI: 7.61 703.81; $p<0.001$ ), and bladder symptoms (adjusted $\mathrm{OR}=30.52 ; 95 \% \mathrm{CI}: 5.95-559.22 ; \quad p=0.001$ ) had a significant relationship with $\mathrm{AD}$ in the elderly population (-Table 5).

Deep breathing test has a significantly high sensitivity of 93.3\% ( $p<0.001)$, and orthostatic HR test has a significantly high specificity of $100 \%(P<0.011)$. The parasympathetic function tests were found to have significantly more sensitivity and specificity when compared with sympathetic tests ( - Table 6 ).

\section{Discussion}

Management of geriatric problems is complicated by a combination of multiple comorbidities, an increasing rate of decline in the physical and social domains, and possible AD. Studying AD in the elderly and managing them effectively are prerequisites for a better quality of life.

It has been reported that both gender and age have an impact on HR variations, with males aged $>50$ years being more prone to AD than females, ${ }^{10}$ and the same was reflected in this study. Although 25 patients in this study did not have comorbidities, AD was seen in 17 (68\%) of them, of whom 14 (56\%) had early AD, clearly indicating age itself to be an independent predictor of AD.

A study conducted by Islam et $\mathrm{al}^{2}$ in healthy elderly patients without comorbidities reported only $23.34 \%$ with
$A D$, and this may indicate that comorbidities in the elderly might contribute substantially to AD. Several studies have also reported that comorbidities increase the severity of ANS disorders. ${ }^{11,12}$ Overall, there is an indication that advancing age is a significant predictor of $\mathrm{AD}$, which increases in severity if associated with comorbidities.

Comorbidity profile of study patients showed that most were hypertensive $(n=58)$ followed by diabetic $(n=52)$. A study by Brij et.al ${ }^{13}$ also reported that hypertension was the prevalent comorbidity. Similar to Kunachgi et al, ${ }^{10}$ the most common symptom of AD in this study was postural hypotension and the least common symptom was sudomotor dysfunction symptoms. In this study, half of those with postural hypotension were on antihypertensive medications. Therefore, orthostatic hypotension in patients receiving antihypertensive treatment could indicate overdose as a differential to suspected AD. ${ }^{14}$

DM and hypertension were noted in $36.87 \%$ and $41.1 \%$ of patients in our study, respectively, and were significantly associated with AD. It compares with the study conducted by Birajdar et $\mathrm{al}^{15}{ }^{15}$ where the prevalence of $\mathrm{AD}$ was $58 \%$ in diabetics. A study conducted by Carthy ${ }^{16}$ also reported that hypertension in elderly patients was associated with significant $\mathrm{AD}$. Of $18 \mathrm{CKD}$ patients in this study, only eight were diabetic, indicating that the cause of AD in CKD patients may not only be associated with DM and that even other comorbidities may contribute. Although the high prevalence of AD could attribute to the disease itself, associated comorbidities (DM, hypertension, and multiple drugs) used in the management of 
Table 3 Association between baseline data and the results of autonomic dysfunction tests

\begin{tabular}{|c|c|c|c|c|c|c|}
\hline \multirow[t]{2}{*}{ Variables } & \multicolumn{5}{|c|}{ Results } & \multirow[t]{2}{*}{$p$-Value } \\
\hline & Normal $(n=37)$ & Early $(n=64)$ & Definitive $(n=14)$ & Severe $(n=19)$ & Atypical $(n=7)$ & \\
\hline \multicolumn{7}{|l|}{ Age (years) } \\
\hline $60-69(n=85)$ & $23(62.2 \%)$ & $41(64.1 \%)$ & $7(50 \%)$ & $9(47.4 \%)$ & $5(71.4 \%)$ & \multirow[t]{3}{*}{0.3} \\
\hline $70-79(n=42)$ & $12(32.4 \%)$ & $16(25 \%)$ & $3(21.4 \%)$ & $9(47.4 \%)$ & $49(29.8 \%)$ & \\
\hline$>80(n=14)$ & $2(5.4 \%)$ & $7(10.9 \%)$ & $4(28.6 \%)$ & $1(5.3 \%)$ & $19(9.9 \%)$ & \\
\hline \multicolumn{7}{|l|}{ Gender } \\
\hline Male $(n=83)$ & $22(59.5 \%)$ & $35(54.7 \%)$ & $9(64.3 \%)$ & $13(68.4 \%)$ & $4(57.1 \%)$ & \multirow[t]{2}{*}{0.9} \\
\hline Female $(n=58)$ & $15(40.5 \%)$ & $29(45.3 \%)$ & $5(35.7 \%)$ & $6(31.6 \%)$ & $3(42.9 \%)$ & \\
\hline \multicolumn{7}{|l|}{ Comorbidities } \\
\hline Diabetes mellitus $(n=52)$ & $21(56.8 \%)$ & $16(25 \%)$ & $4(28.6 \%)$ & $9(47.4 \%)$ & $2(28.6 \%)$ & $0.01^{\mathrm{a}}$ \\
\hline Hypertension $(n=58)$ & $9(24.3 \%)$ & $31(48.4 \%)$ & $8(57.1 \%)$ & $9(47.4 \%)$ & $1(14.3 \%)$ & $0.04^{a}$ \\
\hline Hypothyroidism $(n=18)$ & $5(13.5 \%)$ & $5(7.8 \%)$ & $2(14.3 \%)$ & $3(15.8 \%)$ & $3(42.9 \%)$ & 0.11 \\
\hline History of IHD $(n=28)$ & $6(16.2 \%)$ & $13(20.3 \%)$ & $3(21.4 \%)$ & $5(26.3 \%)$ & $1(14.3 \%)$ & 0.89 \\
\hline History of CVA $(n=17)$ & $4(10.8 \%)$ & $11(17.2 \%)$ & 0 & $1(5.3 \%)$ & $1(14.3 \%)$ & 0.39 \\
\hline CKD $(n=18)$ & $1(2.7 \%)$ & $8(12.5 \%)$ & $3(21.4 \%)$ & $4(21.1 \%)$ & $2(28.6 \%)$ & 0.06 \\
\hline $\operatorname{COPD}(n=22)$ & $3(8.1 \%)$ & $9(14.1 \%)$ & $2(14.3 \%)$ & $6(31.6 \%)$ & $2(28.6 \%)$ & 0.15 \\
\hline Bronchial asthma $(n=6)$ & $2(5.4 \%)$ & $4(6.3 \%)$ & 0 & 0 & 0 & 0.90 \\
\hline Chronic liver disease $(n=13)$ & $4(10.8 \%)$ & $4(6.3 \%)$ & $2(14.3 \%)$ & $2(10.5 \%)$ & $1(14.3 \%)$ & 0.60 \\
\hline Cancer $(n=3)$ & 0 & $1(1.6 \%)$ & 0 & $2(10.5 \%)$ & 0 & 0.20 \\
\hline Heart failure $(n=9)$ & 0 & $5(7.8 \%)$ & $1(7.1 \%)$ & $2(10.5 \%)$ & $1(14.3 \%)$ & 0.18 \\
\hline \multicolumn{7}{|l|}{ Number of comorbidities } \\
\hline $0(n=25)$ & 0 & $2(14.3 \%)$ & $14(21.9 \%)$ & $8(\%)$ & $1(5.3 \%)$ & \multirow[t]{6}{*}{0.113} \\
\hline $1(n=39)$ & $4(57.1 \%)$ & $3(21.4 \%)$ & $17(26.6 \%)$ & $10(\%)$ & $5(26.3 \%)$ & \\
\hline $2(n=41)$ & $1(14.3 \%)$ & $6(42.9 \%)$ & $16(25 \%)$ & $13(35.1 \%)$ & $5(26.3 \%)$ & \\
\hline $3(n=24)$ & 0 & $2(14.3 \%)$ & $11(17.2 \%)$ & $5(13.5 \%)$ & $6(31.6 \%)$ & \\
\hline $4(n=9)$ & $2(28.6 \%)$ & $1(7.1 \%)$ & $5(7.8 \%)$ & $1(2.7 \%)$ & 0 & \\
\hline $5(n=3)$ & 0 & 0 & $1(1.6 \%)$ & 0 & $2(10.5 \%)$ & \\
\hline \multicolumn{7}{|l|}{ Symptoms of AD } \\
\hline Postural hypotension $(n=40)$ & $12(32.4 \%)$ & $14(21.9 \%)$ & $2(14.3 \%)$ & $10(52.6 \%)$ & $2(28.6 \%)$ & \multirow[t]{4}{*}{0.102} \\
\hline $\begin{array}{l}\text { Gastrointestinal symptoms } \\
(n=21)\end{array}$ & $5(13.5 \%)$ & $9(14.1 \%)$ & $3(21.4 \%)$ & $3(15.8 \%)$ & $1(14.3 \%)$ & \\
\hline Bladder symptoms $(n=18)$ & $3(8.1 \%)$ & $10(15.6 \%)$ & $1(7.1 \%)$ & $4(21.1 \%)$ & 0 & \\
\hline Sudomotor symptoms $(n=2)$ & 0 & $1(1.6 \%)$ & 0 & $1(5.3 \%)$ & 0 & \\
\hline \multicolumn{7}{|l|}{ Number of AD symptoms } \\
\hline $0(n=79)$ & $22(59.5 \%)$ & $36(56.3 \%)$ & $11(78.6 \%)$ & $6(31.6 \%)$ & $4(57.1 \%)$ & \multirow[t]{3}{*}{$0.04^{a}$} \\
\hline $1(n=43)$ & $10(27 \%)$ & $22(34.4 \%)$ & 0 & $8(42.1 \%)$ & $3(42.9 \%)$ & \\
\hline $2(n=19)$ & $5(13.5 \%)$ & $6(9.4 \%)$ & $3(21.4 \%)$ & $5(26.3 \%)$ & 0 & \\
\hline \multicolumn{7}{|l|}{ HbA1c (glycated hemoglobin) } \\
\hline$<7 \%(n=24)$ & $7(18.9 \%)$ & $8(12.5 \%)$ & $3(21.4 \%)$ & $5(26.3 \%)$ & $1(14.3 \%)$ & \multirow[t]{3}{*}{$0.03^{a}$} \\
\hline $7-9 \%(n=20)$ & $10(27 \%)$ & $8(12.5 \%)$ & $1(7.1 \%)$ & 0 & $1(14.3 \%)$ & \\
\hline$>9 \%(n=8)$ & $4(10.8 \%)$ & 0 & 0 & $4(21.1 \%)$ & 0 & \\
\hline
\end{tabular}

Abbreviations: CKD, chronic kidney disease; COPD, chronic obstructive pulmonary disorder; CVA, cerebrovascular accident; IHD, ischemic heart disease.

asignificant.

CKD may increase the severity of AD. A study conducted in the United Kingdom also reported that $A D$ in CKD is a predictor of mortality and that $\mathrm{AD}$ worsens as CKD progresses to end-stage renal disease. ${ }^{17} \mathrm{HbA} 1 \mathrm{c}>9 \%$ in the majority of diabetic patients in this study found no association with age, although a study by Dubowitz et a ${ }^{18}$ found age-related increase in HbA1c.
Deeper analysis by logistic regression in this study found that the high prevalence of ANS dysfunction in the elderly may not be entirely due to their age but also due to the associated comorbidities. The factors that significantly influenced $\mathrm{AD}$ in the elderly population in this study were the presence of DM and gastrointestinal and bladder abnormalities. 
Table 4 Association between autonomic function tests and results of autonomic dysfunction tests

\begin{tabular}{|c|c|c|c|c|c|c|}
\hline \multirow[t]{2}{*}{ Criteria } & \multicolumn{5}{|c|}{ Results } & \multirow[t]{2}{*}{$p$-Value } \\
\hline & Normal $(n=37)$ & Early $(n=64)$ & Definitive $(n=14)$ & Severe $(n=19)$ & Atypical $(n=7)$ & \\
\hline \multicolumn{7}{|l|}{ Deep breathing test } \\
\hline Normal $(n=37)$ & $30(81.1 \%)$ & $6(9.4 \%)$ & 0 & $1(5.3 \%)$ & 0 & \multirow[t]{3}{*}{$<0.001^{a}$} \\
\hline Borderline $(n=20)$ & $7(18.9 \%)$ & $12(18.8 \%)$ & 0 & $1(5.3 \%)$ & 0 & \\
\hline Abnormal $(n=84)$ & 0 & $46(71.9 \%)$ & $14(100 \%)$ & 17 (89.5\%) & $7(100 \%)$ & \\
\hline \multicolumn{7}{|l|}{ Valsalva ratio } \\
\hline Normal $(n=64)$ & $32(86.5 \%)$ & $26(40.6 \%)$ & 0 & 0 & $6(85.7 \%)$ & \multirow[t]{3}{*}{$<0.001^{\mathrm{a}}$} \\
\hline Borderline $(n=42)$ & $5(13.5 \%)$ & 35 (54.7\%) & 0 & $1(5.3 \%)$ & $1(14.3 \%)$ & \\
\hline Abnormal $(n=35)$ & 0 & $3(4.7 \%)$ & $14(100 \%)$ & 18 (94.7\%) & 0 & \\
\hline \multicolumn{7}{|l|}{ Orthostatic heart rate } \\
\hline Normal $(n=125)$ & $37(100 \%)$ & $59(92.2 \%)$ & $14(100 \%)$ & $8(42.1 \%)$ & $7(100 \%)$ & \multirow[t]{3}{*}{$<0.001^{\mathrm{a}}$} \\
\hline Borderline $(n=7)$ & 0 & $2(3.1 \%)$ & 0 & $5(26.3 \%)$ & 0 & \\
\hline Abnormal $(n=9)$ & 0 & $3(4.7 \%)$ & 0 & $6(31.6 \%)$ & 0 & \\
\hline \multicolumn{7}{|l|}{ Isometric handgrip test } \\
\hline Normal $(n=67)$ & $26(70.3 \%)$ & $32(50 \%)$ & $8(57.1 \%)$ & $1(5.3 \%)$ & 0 & \multirow[t]{3}{*}{$<0.001^{\mathrm{a}}$} \\
\hline Borderline $(n=51)$ & $11(29.7 \%)$ & $30(46.9 \%)$ & $6(42.9 \%)$ & $3(15.8 \%)$ & $1(14.3 \%)$ & \\
\hline Abnormal $(n=23)$ & 0 & $2(\%)$ & 0 & $15(\%)$ & $6(85.7 \%)$ & \\
\hline \multicolumn{7}{|c|}{ Orthostatic blood pressure } \\
\hline Normal $(n=114)$ & $31(83.8 \%)$ & $54(84.4 \%)$ & $12(85.7 \%)$ & $10(52.6 \%)$ & $7(100 \%)$ & \multirow[t]{3}{*}{$<0.001^{a}$} \\
\hline Borderline $(n=23)$ & $6(16.2 \%)$ & $10(15.6 \%)$ & $1(14.3 \%)$ & $5(26.3 \%)$ & 0 & \\
\hline Abnormal $(n=4)$ & 0 & 0 & 0 & $4(21.1 \%)$ & 0 & \\
\hline
\end{tabular}

aHighly significant.

AFTs based on HR differences are more suitable than BP response tests for the assessment of autonomic disturbances in the elderly, ${ }^{10}$ and the same was seen in this study as well. Although the Valsalva maneuver tests the integrity of both sympathetic and parasympathetic divisions of the ANS, it is more of a parasympathetic test. Similar to other studies, the Valsalva ratio that has been widely used as a test of cardiovagal and baroreceptor function declined with advancing age in the geriatric population. ${ }^{6} 19$ Orthostatic response HR decreased with age in this study, although not significantly. The same was observed in a study by Islam et $\mathrm{al}^{2}{ }^{2}$ whereas other studies found a significant decrease in the ratio of $R R$ intervals as the age advanced. ${ }^{6,19}$

In this study, the BP response to standing was in contrast to Islam et al, ${ }^{2}$ where they found a statistically significant association between orthostatic BP and AD. Similar to this study, an earlier study by Vijitha et $\mathrm{a}^{19}$ also did not find a significant decline in BP response to sustained handgrip test in the elderly, whereas Kunachgi et al ${ }^{10}$ observed a decreased BP response to sustained handgrip test in older patients due to reduced effector organ sensitivity. Previous studies also found a significant reduction in both parasympathetic (HR response to deep breathing, Valsalva maneuver, orthostatic position) and sympathetic (BP response to sustained handgrip and orthostatic position) components to $\mathrm{AD}$ tests. ${ }^{2,10,19}$ However, in this study, the decline in parasympathetic function was more than the decline in sympathetic function, indicating that HR variability tests may be more suitable than sympathetic tests for the assessment of AD in the elderly.

Sensitivity and specificity of the tests were higher for the tests based on HR (parasympathetic), that is, deep breathing test $(93.3 \%$ sensitivity) and orthostatic HR test (100\% specificity), than tests based on BP response. In this study, it was noticed that there was a decline in HR response to deep breathing as determined by the $\mathrm{E} / \mathrm{I}$ (expiration/inspiration) ratio, in corroboration with other studies. ${ }^{6,19}$

Overall, this study indicates that although age is a predictor of $A D$, it increases the severity of $A D$ if associated with comorbidities. Moreover, to the best of our knowledge, this is the first study that determines the sensitivity, specificity, PPV, NPV, and accuracy of AFTs to assess AD in elderly patients with different comorbidity profiles.

Previous studies have compared older patients ( $>60$ years) with younger age groups ( $<50$ years) and showed statistically significant results; however, we did not perform such a comparison. ${ }^{2,6,9,10}$ Therefore, future studies can be designed to compare $\mathrm{AD}$ in older patients with younger age groups with comorbidities to validate the current findings. The American Academy of Neurology has stated that functions of ANS must be determined in three domains (sympathetic, parasympathetic, and sudomotor functions ${ }^{20}$; therefore, future studies can evaluate the sudomotor functions as well in the elderly patients. 
Table 5 Factors affecting autonomic function in the elderly population

\begin{tabular}{|c|c|c|c|c|c|c|}
\hline \multirow{2}{*}{\multicolumn{2}{|c|}{ Variables }} & \multicolumn{2}{|c|}{$\begin{array}{l}\text { Symptoms of autonomic } \\
\text { dysfunction, } N=141\end{array}$} & \multirow[t]{2}{*}{$p$-Value } & \multirow[t]{2}{*}{ Odds ratio $(95 \% \mathrm{Cl})$} & \multirow[t]{2}{*}{$p$-Value } \\
\hline & & Yes & No & & & \\
\hline \multicolumn{7}{|l|}{ Comorbidities } \\
\hline \multirow[t]{2}{*}{ Diabetes mellitus } & Yes & 30 & 22 & \multirow[t]{2}{*}{$0.01^{\mathrm{a}}$} & \multirow[t]{2}{*}{$2.55(1.27-5.20)$} & \multirow[t]{2}{*}{$<0.01^{\mathrm{a}}$} \\
\hline & No & 31 & 58 & & & \\
\hline \multirow[t]{2}{*}{ CKD } & Yes & 5 & 13 & \multirow[t]{2}{*}{0.24} & \multirow[t]{2}{*}{$0.46(0.14-1.30)$} & \multirow[t]{2}{*}{0.16} \\
\hline & No & 56 & 67 & & & \\
\hline \multirow[t]{3}{*}{ CLD } & Yes & 8 & 5 & \multirow[t]{3}{*}{0.27} & \multirow[t]{3}{*}{$2.26(0.71-7.85)$} & \multirow[t]{3}{*}{0.17} \\
\hline & No & 53 & 75 & & & \\
\hline & No & 59 & 80 & & & \\
\hline \multirow[t]{2}{*}{ Hypertension } & Yes & 28 & 30 & \multirow[t]{2}{*}{0.40} & \multirow[t]{2}{*}{$1.41(0.71-2.79)$} & \multirow[t]{2}{*}{0.31} \\
\hline & No & 33 & 50 & & & \\
\hline \multirow[t]{2}{*}{ Hypothyroidism } & Yes & 7 & 11 & \multirow[t]{2}{*}{0.88} & \multirow[t]{2}{*}{$0.81(0.28-2.20)$} & \multirow[t]{2}{*}{0.688} \\
\hline & No & 54 & 69 & & & \\
\hline \multirow[t]{2}{*}{ IHD } & Yes & 11 & 17 & \multirow[t]{2}{*}{0.79} & \multirow[t]{2}{*}{$0.81(0.34-1.87)$} & 0.63 \\
\hline & No & 50 & 63 & & & \\
\hline CVA & Yes & 7 & 10 & $\sim 1$ & $0.90(0.31-2.51)$ & 0.85 \\
\hline & No & 54 & 70 & & & \\
\hline COPD & Yes & 11 & 11 & 0.64 & $1.38(0.54-3.46)$ & 0.48 \\
\hline & No & 50 & 69 & & & \\
\hline Bronchial asthma & Yes & 2 & 4 & 0.71 & $0.64(0.08-3.41)$ & 0.61 \\
\hline & No & 59 & 76 & & & \\
\hline Cancer & Yes & 2 & 1 & 0.56 & $2.67(0.25-58.43)$ & 0.42 \\
\hline & No & 59 & 79 & & & \\
\hline Heart failure & Yes & 4 & 5 & $\sim 1$ & $1.05(0.25-4.15)$ & 0.94 \\
\hline & No & 57 & 75 & & & \\
\hline Symptoms & & & & & & \\
\hline Postural hypotension & Yes & 40 & 0 & $<0.001^{a}$ & $1.1976^{\mathrm{a}} 10^{+09}$ & 0.99 \\
\hline & No & 21 & 80 & & $\begin{array}{l}\left(1.8484^{\mathrm{a}} 10^{-24} \text { to }\right. \\
\left.3.0827^{\mathrm{a}} 10^{+245}\right)\end{array}$ & \\
\hline Gastrointestinal & Yes & 20 & 1 & $<0.001^{a}$ & $38.53(7.61-703.81)$ & $<0.001^{a}$ \\
\hline Symptoms & No & 41 & 79 & & & \\
\hline Bladder symptoms & Yes & 17 & 1 & $<0.001^{a}$ & $30.52(5.95-559.22)$ & $<0.01^{\mathrm{a}}$ \\
\hline & No & 44 & 79 & & & \\
\hline Sudomotor symptoms & Yes & 2 & 0 & 0.20 & $\begin{array}{l}7.8072^{\mathrm{a}} 10^{+06} \\
\left(5.5272^{\mathrm{a}} 10-64-N A\right)\end{array}$ & 0.98 \\
\hline
\end{tabular}

Abbreviations: Cl, confidence interval; CKD, chronic kidney disease; CLD, chronic Liver Disease; COPD, chronic obstructive pulmonary disorder; CVA, cardiovascular accident; IHD, ischemic heart disease.

asignificant.

\section{Conclusions}

The study highlights that age itself is a predictor of $\mathrm{AD}$, which may increase in severity if associated with comorbidities such as DM, hypertension, and CKD. For a successful management of geriatric population with $\mathrm{AD}$, the comorbidity profile must also be considered to improve the patient's quality of life. AFTs are simple, noninvasive, and inexpensive tests that can be used to assess the status of the ANS and AD severity in the elderly. Hence, further studies with a large sample size are required to assess the prevalence of $\mathrm{AD}$ in the elderly as it contributes independently to their morbidity irrespective of their comorbidities. 
Table 6 SE, SP, PPV, and NPV of AFTs

\begin{tabular}{|c|c|c|c|c|c|c|c|c|c|c|}
\hline \multirow[t]{2}{*}{ AFT } & \multicolumn{4}{|c|}{$\begin{array}{l}\text { Observation, } \\
N=141\end{array}$} & \multicolumn{6}{|c|}{ Correlation } \\
\hline & TP & FP & FN & $\mathrm{TN}$ & SE & SP & PPV & NPV & Accuracy & $p$-Value \\
\hline Deep breathing test & 97 & 7 & 7 & 30 & $93.3 \%$ & $81.1 \%$ & $93.3 \%$ & $81.1 \%$ & $90.1 \%$ & $<0.001^{a}$ \\
\hline Valsalva ratio & 70 & 7 & 32 & 32 & $68.6 \%$ & $82.1 \%$ & $90.9 \%$ & $50 \%$ & $72.3 \%$ & $<0.001^{a}$ \\
\hline $\begin{array}{l}\text { Orthostatic Heart } \\
\text { rate }\end{array}$ & 16 & 0 & 88 & 37 & $15.4 \%$ & $100 \%$ & $100 \%$ & $29.6 \%$ & $37.6 \%$ & $<0.011^{\mathrm{a}}$ \\
\hline $\begin{array}{l}\text { Isometric handgrip } \\
\text { test }\end{array}$ & 63 & 11 & 41 & 26 & $60.6 \%$ & $70.3 \%$ & $85.1 \%$ & $38.8 \%$ & $63.1 \%$ & $<0.001^{\mathrm{a}}$ \\
\hline $\begin{array}{l}\text { Orthostatic blood } \\
\text { pressure }\end{array}$ & 21 & 6 & 83 & 31 & $20.2 \%$ & $83.8 \%$ & $77.8 \%$ & $27.2 \%$ & $36.9 \%$ & 0.597 \\
\hline
\end{tabular}

Abbreviations: AFT, autonomic function test; FN, false negative; FP, false positive; NPV, negative predictive value; PPV, positive predictive value; SE, sensitivity; SP, specificity; TN, true negative; TP, true positive.

aHighly significant.

\section{Funding}

None.

\section{Conflict of Interest}

None declared.

\section{Acknowledgments}

All the authors have contributed equally in the development of the manuscript.

\section{References}

1 Marigold J, Arias M, Vassallo M, Allen S, Kwan J. Autonomic dysfunction in older people. Rev Clin Gerontol 2011;21:28-44

2 Islam $\mathrm{T}$, Begum N, Ferdousi S. Autonomic neuropathy in healthy elderly person. J Bangladesh Soc Physiol 2013;8:77-83

3 Engstrom J, Martin J, Disorders of the autonomic nervous system. In: Braunwald E, Fauci A, Kasper D, Hauser S, Longo D, Jameson J, eds. Harrison's Principles of Internal Medicine. New York, NY: McGraw-Hill; 2001:2416-2420

4 Kovács L, Papós M, Takács R, et al. Autonomic nervous system dysfunction involving the gastrointestinal and the urinary tracts in primary Sjögren's syndrome. Clin Exp Rheumatol 2003 ;21(6):697-703

5 Tessa C, Toschi N, Orsolini S, et al. Central modulation of parasympathetic outflow is impaired in de novo Parkinson's disease patients. PLoS One 2019;14(1):e0210324

6 Parashar R, Amir M, Pakhare A, Rathi P, Chaudhary L. Age related changes in autonomic functions. J Clin Diagn Res 2016;10(3): CC11-CC15

7 Moodithaya S, Avadhany ST. Gender differences in age-related changes in cardiac autonomic nervous function. J Aging Res 2012;2012:679345

8 Ewing DJ, Clarke BF. Diagnosis and management of diabetic autonomic neuropathy. Br Med J (Clin Res Ed) 1982;285(6346): 916-918
9 MS VS, Veeraiah S. Age related changes in the parasympathetic control of the heart. International Journal of Scientific and Research Publication 2012;2:1-6

10 Kunachgi PN, Bhadra RC, Mallikarjuna RC. A study of autonomic dysfunction in elderly age. Ann Int Med Dent Res 2015;1:209-212

11 Yang Y, Lee EY, Cho JH, et al. Cardiovascular autonomic neuropathy predicts higher HbA1c variability in subjects with type 2 diabetes mellitus. Diabetes Metab J 2018;42(6):496-512

12 Lai YR, Huang CC, Chiu WC, et al. HbA1C variability is strongly associated with the severity of cardiovascular autonomic neuropathy in patients with Type 2 diabetes after longer diabetes duration. Front Neurosci 2019;13:458

13 Brij BT, Bidhu KM, Narendra KB, Priya T, Danish N, Vinod R. A profile of common morbidities among geriatric population attending at a new tertiary care institute. Ann Int Med Dent Res 2017;3:32-41

14 Kasper D, Fauci A, Hauser S, Longo D, Jameson J, Loscalzo J, Harrison's Principles of Internal Medicine. 19th ed. New York, NY: McGraw-Hill; 2015

15 Birajdar SV, Chavan SS, Munde SA, Bende YP. A study of autonomic nervous system dysfunction among patient with diabetes mellitus: a cross sectional study. Int J Adv Med 2017;4 406-411

16 Carthy ER. Autonomic dysfunction in essential hypertension: a systematic review. Ann Med Surg (Lond) 2013;3(1):2-7

17 Robinson TG, Carr SJ. Cardiovascular autonomic dysfunction in uremia. Kidney Int 2002;62(6):1921-1932

18 Dubowitz N, Xue W, Long Q, et al. Aging is associated with increased HbA1c levels, independently of glucose levels and insulin resistance, and also with decreased HbA1c diagnostic specificity. Diabet Med 2014;31(8):927-935

19 Vijitha P, Sailaja M, Reddy N. Study of autonomic function tests in geriatric population. Int J Intg Med Sci 2015;2:79-86

20 Gibbons $\mathrm{CH}$, Cheshire WP Jr, Fife TD, Autonomic testing. In: Model Coverage Policy. Minneapolis, MN: American Academy of Neurology; 2014:1-10 